\title{
Research of professional suitability in construction by the noise factor
}

\author{
Lilia Kireeva ${ }^{1, *}$, Tatiana Kaverzneva ${ }^{1}$, Dmitriy Tarkhov $^{1}$, and Natalia Belina ${ }^{1}$ \\ ${ }^{1}$ Peter the Great St. Petersburg Polytechnic University, Polytechnicheskaya 29, St. Petersburg, \\ 195251, Russian Federation
}

\begin{abstract}
The field of construction is one of the most traumatic areas of human activity. Various methods are used to reduce injuries and increase the safety level at construction sites, which do not allow to reduce the level of injury risk. In other industries characterized by heightened danger, the risk management methodology based on the "human factor" management is gaining popularity. By attracting the most relevant workers, we can compensate for a significant portion of the risks. The authors propose the use this concept in the field of construction. In this paper, a study of professional fitness in construction during work requiring an increased level of attention and reaction under the influence of noise factor was conducted. For this purpose, testing was per-formed to identify the dependencies between the external effects of noise and attention indicators. During the testing the subjects demonstrated various concentration abilities. We concluded that, using this methodology, it is possible to select "successfully fit" personnel to perform specific tasks in construction, in order to increase the level of safety.
\end{abstract}

\section{Introduction}

The field of construction has long been positioned in the status of one of the most traumatic areas of human activity. In an attempt to reduce injuries on construction sites, addition-al measures aimed at improving the skills and disciplines of construction personnel, organizational methods of managing injuries are being developed [1-8]. There are widespread special restrictions on the performance of a number of high-risk works. Increasingly, technologies that make it possible to eliminate or minimize the performance of a high-risk job are being introduced $[9,10]$. Nevertheless, the construction process today does not allow to abandon workers on the construction site, including the performance of heightened danger work. More and more research is being directed towards developing risk management methodologies that take into account human actions. Risk management based on the management of the "human factor" allows you to achieve higher safety performance in other areas associated with increased risk [11-15]. However, the list of industries where such methodologies are applied today does not seem that big. The authors believe that the selection of workers whose professionally important qualities fully meet the requirements

\footnotetext{
* Corresponding author: la.savchenkova@yandex.ru
} 
of the profession ("successfully fit"), will reduce the risk of accidents and injuries at construction sites.

One of the most common harmful factors on the construction site is the noise factor. In addition to the general negative impact of noise on a person's hearing organs, the impact of noise has an extremely negative effect on the work of the central nervous system. In conditions of increased noise, the reaction rate slows down, attention indicators deteriorate, which leads to an increase in the number of accidents [16-19]. By attracting to work requiring increased concentration of attention and the ability to quickly and correctly react to the current situation (welders, special equipment operators, responsible executors of hazardous work), workers who have higher indicators of attention can be offset by a significant portion of the risks in performing hazardous work.

This work is aimed at studying the professional suitability in construction during the work that requires an increased level of attention and reaction when exposed to noise. To this end, a test was conducted to identify the dependencies between the external influence of the noise factor and the attention indicators and, based on the test results, the professional suitability of the workers being tested was assessed, and conclusions were made about the impact of the noise factor on the professional suitability of work requiring an increased level of attention for the construction industry.

\section{Materials and methods}

A test was conducted to identify the relationship between the external influence of noise factor and attention indicators. [20]. The group of subjects consisted of 30 representatives of the construction area, men from 23 to 47 years old. Experience in the construction of the subjects varied from 7 months to 16 years. Testing was conducted in three stages. The first test package (hereinafter referred to as the "control package") was carried out without external irritant effect; further the results of noise exposure were compared to it. The second packet (hereinafter referred to as the "permanent packet") was carried out under the continuous influence of constant noise with a sound level of $70 \mathrm{dBA}$. The noise produced by the generator was taken as an annoying factor. The third test package ("impulse package") is performed under the influence of impulse noise emitted by a metronome.

Each package included 2 tests (the Schulte table and Thorndike's test) aimed at identifying indicators of attention. [20,21]. The time spent on visual processing of a thousand and a half characters and the number of errors (missing characters, incorrectly selected characters) was estimated.

To analyze the results, neural network smoothing of an ordered sample of results was used, which allowed smoothing the obtained sample and revealing its characteristic features. A perceptron with one hidden layer and an activation function $[22,23]$ was used.

\section{Results}

Schulte tables are designed to estimate the amount of dynamic attention. This technique can be used to identify the speed of the orienting search movements of eyes, to study the extent of attention [20,21].

Table 1. Values of runtime test №1

\begin{tabular}{|c|c|c|}
\hline $\begin{array}{c}\text { Control package, } \\
\text { min: } \mathrm{s}\end{array}$ & $\begin{array}{c}\text { Constant package, } \\
\text { min: } \mathrm{s}\end{array}$ & $\begin{array}{c}\text { Impulse package, } \\
\text { min: } \mathrm{s}\end{array}$ \\
\hline $00: 18.5$ & $00: 16.0$ & $00: 16.2$ \\
\hline $00: 23.6$ & $00: 19.9$ & $00: 17.0$ \\
\hline $00: 24.2$ & $00: 23.9$ & $00: 19.1$ \\
\hline
\end{tabular}




\section{EECE-2018}

\begin{tabular}{|c|c|c|}
\hline $00: 24.9$ & $00: 24.3$ & $00: 19.9$ \\
\hline $00: 25.5$ & $00: 24.8$ & $00: 22.0$ \\
\hline $00: 26.0$ & $00: 25.3$ & $00: 23.7$ \\
\hline $00: 26.6$ & $00: 25.4$ & $00: 23.7$ \\
\hline $00: 26.9$ & $00: 25.9$ & $00: 24.6$ \\
\hline $00: 27.7$ & $00: 26.4$ & $00: 25.2$ \\
\hline $00: 28.1$ & $00: 26.7$ & $00: 25.4$ \\
\hline $00: 28.7$ & $00: 27.1$ & $00: 26.6$ \\
\hline $00: 28.9$ & $00: 27.8$ & $00: 26.7$ \\
\hline $00: 29.3$ & $00: 27.9$ & $00: 27.0$ \\
\hline $00: 29.5$ & $00: 28.6$ & $00: 27.1$ \\
\hline $00: 30.3$ & $00: 28.7$ & $00: 27.1$ \\
\hline $00: 30.4$ & $00: 29.2$ & $00: 27.5$ \\
\hline $00: 30.7$ & $00: 29.9$ & $00: 27.5$ \\
\hline $00: 31.7$ & $00: 30.0$ & $00: 28.6$ \\
\hline $00: 32.1$ & $00: 30.7$ & $00: 29.2$ \\
\hline $00: 33.2$ & $00: 31.1$ & $00: 30.5$ \\
\hline $00: 34.9$ & $00: 31.7$ & $00: 31.2$ \\
\hline $00: 35.3$ & $00: 32.1$ & $00: 31.2$ \\
\hline $00: 35.5$ & $00: 32.1$ & $00: 31.5$ \\
\hline $00: 36.8$ & $00: 33.0$ & $00: 31.5$ \\
\hline $00: 37.7$ & $00: 33.1$ & $00: 31.8$ \\
\hline $00: 39.2$ & $00: 33.7$ & $00: 34.8$ \\
\hline $00: 40.6$ & $00: 34.4$ & $00: 37.3$ \\
\hline $00: 42.7$ & $00: 34.8$ & $00: 37.4$ \\
\hline $00: 44.6$ & $00: 36.9$ & $00: 38.0$ \\
\hline $00: 44.9$ & $00: 39.6$ & $00: 39.3$ \\
\hline
\end{tabular}

The average values of test №1: control package - 00: 31.6 s., the constant package - 00: $29.0 \mathrm{~s}$, the impulse package - 00: $28.0 \mathrm{~s}$. The results indicate a phenomenon of adaptation to the task. The impact of external noise, both constant and impulse, does not significantly affect the execution time. However, the step of reducing the average time to complete the test is significantly different, which suggests that there is a distracting effect of external noise.

The use of neural network smoothing of an ordered sample of test results No. 1 made it possible to reveal its characteristic features presented in Figure 1.

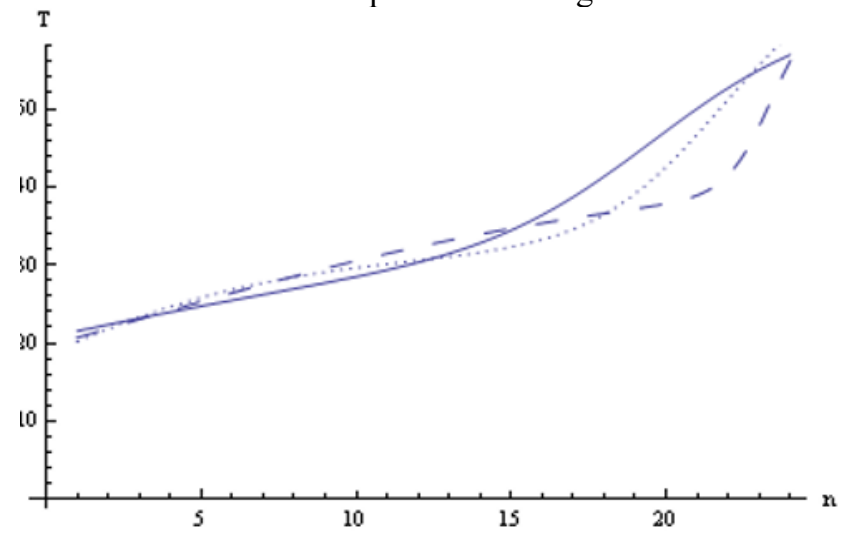


Fig. 1. Dependence of the execution time T, from test No. 1 on the number of participants $n$ in the ranked set (the solid line is the control package, the dotted line is the permanent package, the dashed line is the impulse package).

Based on the chart, conclusions were made that conditionally the subjects can be divided into three groups. Subjects of the first group were able to focus and hold their attention. The influence of external annoying noise factors on them was minimal; subjects of the second group felt the effects of noise, which affected the test results; subjects of the third group experienced difficulty in mastering the control task and the phenomenon of "adaptation" was observed.

Thorndike's test determines the stability of attention during simple, but monotonous work. Sustainability is characterized by the resistance to fluctuations from external or internal stimuli, that is, a given activity rate must remain uniform throughout the entire period of work $[20,21]$.

Table 2. Values of runtime test №2

\begin{tabular}{|c|c|c|}
\hline $\begin{array}{c}\text { Control package, } \\
\text { min: s }\end{array}$ & $\begin{array}{c}\text { Constant package, } \\
\text { min: s }\end{array}$ & $\begin{array}{l}\text { Impulse package, } \\
\text { min: s }\end{array}$ \\
\hline $01: 38.2$ & $01: 18.1$ & $00: 55.0$ \\
\hline $01: 47.5$ & $01: 13.9$ & $01: 59.9$ \\
\hline $01: 47.9$ & $02: 20.6$ & $02: 28.2$ \\
\hline $02: 00.4$ & 01:09.4 & $02: 05.7$ \\
\hline $02: 00.9$ & $01: 41.3$ & $02: 08.9$ \\
\hline $02: 13.2$ & $01: 48.1$ & $02: 09.4$ \\
\hline $02: 14.7$ & $01: 32.0$ & $02: 14.3$ \\
\hline $02: 16.9$ & $02: 10.8$ & $02: 10.6$ \\
\hline $02: 22.9$ & $01: 53.9$ & $02: 33.8$ \\
\hline $02: 44.6$ & $02: 37.7$ & $02: 37.7$ \\
\hline $02: 47.4$ & $02: 12.8$ & $02: 25.1$ \\
\hline $02: 48.5$ & $01: 55.5$ & $02: 42.3$ \\
\hline $02: 48.9$ & $02: 15.5$ & $02: 45.1$ \\
\hline $02: 53.7$ & $02: 39.3$ & $02: 49.8$ \\
\hline $02: 58.5$ & $02: 16.0$ & $02: 46.3$ \\
\hline $02: 59.8$ & $02: 48.2$ & $02: 32.9$ \\
\hline $03: 00.2$ & $02: 19.1$ & $02: 48.3$ \\
\hline $03: 07.1$ & $02: 42.2$ & $03: 02.2$ \\
\hline $03: 10.5$ & $03: 18.6$ & $02: 33.6$ \\
\hline $03: 32.2$ & $02: 34.8$ & $02: 50.1$ \\
\hline $03: 44.3$ & $03: 06.5$ & $03: 17.4$ \\
\hline $03: 44.9$ & $03: 10.7$ & $03: 23.6$ \\
\hline $03: 45.3$ & $03: 17.2$ & $03: 34.6$ \\
\hline $03: 45.4$ & $03: 12.9$ & $02: 51.3$ \\
\hline $03: 53.8$ & $03: 19.2$ & $04: 14.0$ \\
\hline 04:00.9 & $03: 22.3$ & $03: 00.3$ \\
\hline 04:01.3 & $03: 25.8$ & $02: 45.9$ \\
\hline 04:02.8 & $03: 38.0$ & $03: 42.2$ \\
\hline $04: 05.8$ & $03: 47.4$ & $03: 50.0$ \\
\hline 04:14.1 & $03: 25.9$ & $03: 15.2$ \\
\hline
\end{tabular}

The average values of test №2: control package - 03:01.1 s., the constant package 02:33.1 s., the impulse package - 02:45.1 s. The conclusions made on the basis of the results of this test coincide with the conclusions of the test results №1. 
The neural network smoothing was also performed for test № 2. The results are presented in Fig. 2

The conclusions made by this graph coincide with the previously expressed idea of the conditional division of the subjects into groups according to their ability to stay focused. However, in this case, there is a pronounced effect of impulse noise, which allows us to conclude that impulsive noise is unacceptable during monotonous work that requires attention.

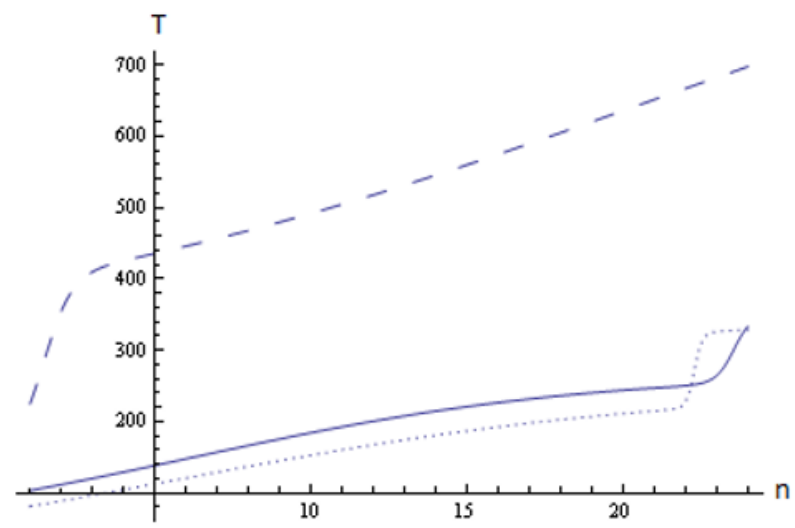

Fig. 2. Dependence of the execution time T, from test No. 2 on the number of participants $n$ in the ranked set (the solid line is the control package, the dotted line is the permanent package, the dashed line is the impulse package).

\section{Discussion}

Analysis of the test results showed the non-linearity of the increase in the number of errors in the percentage. Over time attention indicators fell. Impulse noise leads to an earlier loss of concentration and a greater increase in the number of errors in fig. 3

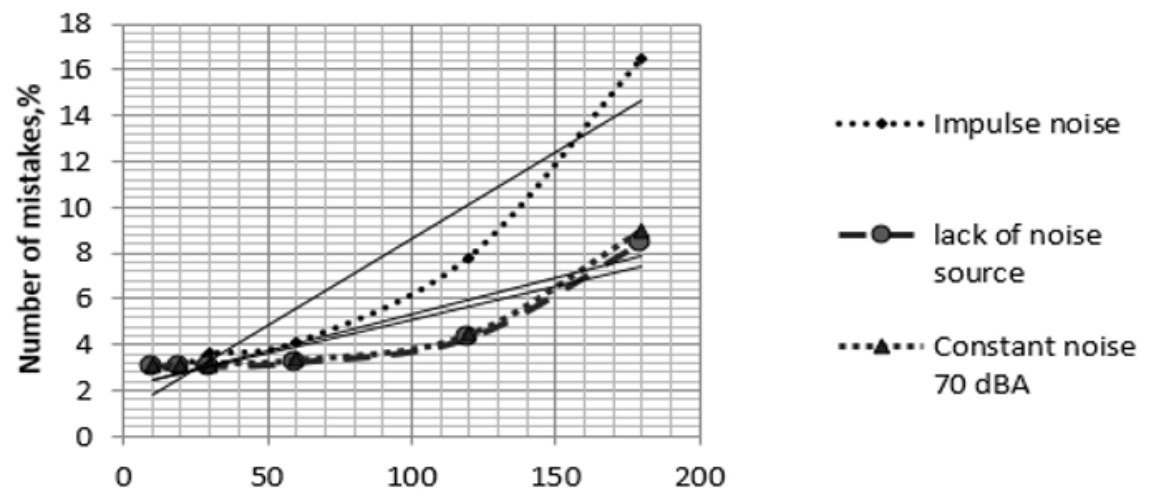

Time, s

Fig. 3. Distribution of the increase in the number of errors over time when exposed to constant, impulse noise and in its absence.

There is an increase in the number of errors when the subjects are exposed to pulse noise by about $15 \%$. At the same time a phenomenon of "adaptation" is observed. A small but sharp increase in the percentage of errors at the beginning of this study, and the 
subsequent smoothing of the graph, indicate of some adaptation of the subjects and the mastery of the task. Then, there is a proportional increase in the percentage of the number of errors caused by the acoustic effect. The increase in the percentage of errors in the background effect of noise slightly exceeds the evaluations of the "control study" and is about $7 \%$. Thus, impulse noise leads to an almost double increase in errors for the considered period of time.

\section{Conclusions}

The subjects during the test showed different concentration abilities in performing various types of tasks. This allows us to conclude that using this technique, it is possible to select "successfully suitable" personnel for performing specific tasks in the construction industry (using the appropriate test) that is resistant to external stimuli.

For greater reliability of the results and more accurate accounting of the type of work being done, it is necessary to increase the sample of values and expand the list of the studied characteristics of workers. This requires testing with a larger number of subjects. Impulse noise has a priority impact on the indicators of attention compared to the constant noise in performing the work that requires concentration.

\section{References}

1. B. McCabe, E. Alderman, Y. Chen, D. Hyatt, A. Shahi, J. Constr. Eng. M., 143 (4) (2017)

2. V. Sousa, N. Almeida, L. Dias, Saf. Sci., 66, 75-86 (2014)

3. D. Tarkhov. T.Kaverzneva, D. Ydrisova, MIAB, 11 (60-2), 244-253 (2015)

4. M. Hallowell A. Veltri, C. Harper, J. Wanberg, S. Rajendran, JSHER, 13 (2), 370-376 (2017)

5. S.F. Martínez, ADAPT bulletin, 19 (2016)

6. K. Pykhtin, T. Simankina, V. Sharmanov, and A. Kopytova, IOP Conf. Ser. Earth Environ. Sci. 90, 12065 (2017).

7. I. Valitova, T. Trofimova, T. Simankina, and E. Stein, MATEC Web Conf. 170, 1068 (2018).

8. I.I. Kovalenko, A.S. Sokolitsyn, and V.P. Semenov, in IEEE International Conference "Quality Management, Transport and Information Security, Information Technologies" 2018, 205-208 (2018).

9. E.E. Ameyaw, Y. Hu, M. Shan, A. P.C. Chan, Y. Le, J. Civ. Eng. Manag., 22, 9911000 (2016)

10. X. Shen, E. Marks, JSHER, 13 (1), 330-336 (2017)

11. E. Glebova. Reducing the risk of accidents and injuries in the oil and gas industry based on the model of professional fitness of operators (dis. Dr. Tech. sci. Gubkin University, Yfa) (2009)

12. A. Bavafa, A. Mahdiyar, A. Marsono, Saf. Sci., 106, 47-56 (2018)

13. V. Shkrabak, V. Serditov, A. Ley, Mat. of the internat. sci. and pract. conf. Ecology. Risk. Safety, 166-167 (2010)

14. V. Varus, S. Lishenko, V. Uvarov, D. Ivanov. Manag. and pers: psych. of manag., socionics and sociology, 2 (122), 46-48 (2013) 
15. I. Prahov, I. Farvaev, A. Bikmetov. Transport and storage of oil prod. and hydrocarbons, 1, 27-30 (2015)

16. V.V. Minaeva, A.V. Gaponenko, International Student Scientific Bulletin, 3(1) (2015)

17. I. Pogonysheva, D. Pogonyshev, A. Krylova, Bulletin Of Nizhnevartovsk State University, 1 (2015)

18. A. Bulanova, E. Turyanskaya, Transport and logistics: innovative development in the conditions of globalization of technological and economic relations, 75-77 (Rostov-onDon, 2017)

19. L. Savchenkova, T.Kaverzneva, D. Tarkhov, Neuro computers: development, application 2, 66-70 (2014)

20. P. Fress, J. Piaget, Experimental Psy, 1 (1986)

21. E. Brunner. Better than super-understanding. Methods of diagnosis and psychocorrection: attention psychology, evaluation tests, developing game exercises, Fenix, Rostov-on-Don, (2006)

22. D.Tarkhov. Neural networks: models and algorithms, Radio Engineering (2014)

23. S. Efremov, T. Kaverzneva, D. Tarkhov Neural network simulation in labor protection St. Petersburg (2014) 